\title{
A football helmet prototype that reduces linear and rotational acceleration with the addition of an outer shell
}

\author{
Scott L. Zuckerman, MD, MPH, ,,2 Bryson B. Reynolds, PhD,,3 Aaron M. Yengo-Kahn, MD,, ${ }^{1,2}$ \\ Andrew W. Kuhn, BA, ${ }^{1}$ Jacob T. Chadwell, BE, ${ }^{4}$ Sarah E. Goodale, BE, ${ }^{4}$ Claire E. Lafferty, BE, ${ }^{4}$ \\ Kyle T. Langford, BE, ${ }^{4}$ Lydia J. McKeithan, BE, ${ }^{4}$ Paul Kirby, BA, ${ }^{1}$ and Gary S. Solomon, PhD ${ }^{1,2}$
}

\begin{abstract}
${ }^{1}$ Vanderbilt Sports Concussion Center and ${ }^{2}$ Department of Neurological Surgery, Vanderbilt University School of Medicine; ${ }^{3}$ Department of Radiology, Vanderbilt University Medical Center; and ${ }^{4}$ Department of Biomedical Engineering, Vanderbilt University, Nashville, Tennessee
\end{abstract}

\begin{abstract}
OBJECTIVE Amid the public health controversy surrounding American football, a helmet that can reduce linear and rotational acceleration has the potential to decrease forces transmitted to the brain. The authors hypothesized that a football helmet with an outer shell would reduce both linear and rotational acceleration. The authors' objectives were to 1) determine an optimal material for a shock-absorbing outer shell and 2) examine the ability of an outer shell to reduce linear and/or rotational acceleration.
\end{abstract}

METHODS A laboratory-based investigation was undertaken using an extra-large Riddell Revolution football helmet. Two materials (Dow Corning Dilatant Compound and Sorbothane) were selected for their non-Newtonian properties (changes in viscosity with shear stress) to develop an outer shell. External pads were attached securely to the helmet at 3 locations: the front boss, the side, and the back. The helmet was impacted 5 times per location at $6 \mathrm{~m} / \mathrm{sec}$ with pneumatic ram testing. Two-sample t-tests were used to evaluate linear/rotational acceleration differences between a helmet with and a helmet without the outer shell.

RESULTS Sorbothane was superior to the Dow Corning compound in force reduction and recovered from impact without permanent deformation. Of 5 different grades, 70-duro (a unit of hardness measured with a durometer) Sorbothane was found to have the greatest energy dissipation and stiffness, and it was chosen as the optimal outer-shell material. The helmet prototype with the outer shell reduced linear acceleration by $5.8 \%$ (from $75.4 \mathrm{~g}$ to $71.1 \mathrm{~g} ; \mathrm{p}<0.001$ ) and $10.8 \%$ (from $89.5 \mathrm{~g}$ to $79.8 \mathrm{~g} ; \mathrm{p}=0.033$ ) at the side and front boss locations, respectively, and reduced rotational acceleration by $49.8 \%$ (from $9312.8 \mathrm{rad} / \mathrm{sec}^{2}$ to $4671.7 \mathrm{rad} / \mathrm{sed}^{2} ; \mathrm{p}<0.001$ ) at the front boss location.

CONCLUSIONS Sorbothane (70 duro) was chosen as the optimal outer-shell material. In the outer-shell prototype helmet, the results demonstrated a 5\%-10\% reduction in linear acceleration at the side and front boss locations, and a $50 \%$ reduction in rotational acceleration at the front boss location. Given the paucity of publicly reported helmet-design literature and the importance of rotational acceleration in head injuries, the substantial reduction seen in rotational acceleration with this outer-shell prototype holds the potential for future helmet-design improvements.

https://thejns.org/doi/abs/10.3171/2018.1.JNS172733

KEYWORDS sport-related concussion; American football; engineering; helmet safety; linear acceleration; rotational acceleration; traumatic brain injury

$\mathrm{S}$ PORT-RELATED concussion (SRC) has become an international public health concern, affecting athletes of all ages and skill levels..$^{20,23}$ In the United States, American football inflicts the greatest burden of SRC because of its popularity and high rate of head impacts and has garnered significant scientific and media attention. ${ }^{21,28}$
Football accounts for $41 \%$ of all high school SRCs, ${ }^{14}$ and within the sport itself, concussion is the most common injury. ${ }^{8}$ Two recent studies estimated the current rate of SRC among high school football players to be 8.2-9.2/10,000 athletic exposures. ${ }^{6,26}$

Head kinematics serve as a surrogate for inertial re-

ABBREVIATIONS EDP = energy-dissipating pod; NCAA = National Collegiate Athletic Association; $S R C=$ sport-related concussion. SUBMITTED November 13, 2017. ACCEPTED January 15, 2018.

INCLUDE WHEN CITING Published online June 29, 2018; DOI: 10.3171/2018.1.JNS172733. 
sponses of the brain and are routinely used to study traumatic brain injury. ${ }^{28}$ Two measures-linear acceleration (which produces transient increases in intracranial pressure) and rotational acceleration (which produces a strain response)-contribute to the probability of sustaining a concussion. ${ }^{27}$ Although often evaluated in tandem, rotational acceleration is thought to be the primary force implicated in concussion and has been noted definitively in severe traumatic brain injury. ${ }^{19,28}$ Furthermore, increased duration of rotation results in decreased brain tolerance and more severe injuries. ${ }^{28}$

Although a reliable biomechanical threshold for SRC has proved elusive to date, several studies have sought to identify this threshold. A study of 48 concussions among 450 football and hockey players revealed a wide range of linear and rotational acceleration values associated with each SRC: mean \pm SD $86.1 \pm 42.6 g$ (range 16.5-177.9g) and $3620 \pm 2166 \mathrm{rad} / \mathrm{sec}^{2}$ (range 183-7589 $\mathrm{rad} / \mathrm{sec}^{2}$ ), respectively. ${ }^{9}$ Forbes et al. ${ }^{12}$ searched the English-language literature and concluded that $3 \%$ of football head impacts were above the average accelerations reported in concussive impacts, yet only $0.02 \%$ of these collisions resulted in an SRC. However, the ability to predict SRC risk based on biomechanics is improving; in their study, Rowson and Duma $^{27}$ introduced a metric that computes overall SRC risk based on peak linear and rotational acceleration. Despite advances in the biomechanics of SRC, primary prevention remains a challenge.

The "holy grail" of SRC prevention in helmeted sports is protective headgear that attenuates both linear and rotational acceleration below still-unknown injury thresholds. Although the literature is replete with accelerometer studies that have measured forces involved in helmeted collisions, these analyses have provided little insight into how to reduce forces transmitted to a player's brain. The scientific literature involving innovative helmet design has been sparse; helmet manufacturers have performed the vast majority of this research but have not published their results in scientific journals. The few innovations that have been reported include designing a personalized helmet, ${ }^{15}$ tethering the helmet to the shoulder pads, ${ }^{22}$ and implementing helmet add-on devices. ${ }^{2}$ Linear acceleration can be attenuated through a thicker, heavier helmet shell; however, this generally comes at the expense of decreased comfort, higher magnitudes of rotational acceleration caused by increased rotational momentum and duration of acceleration, and increased force because of increased mass.

Given the lack of public research into new football helmet design, we conducted a laboratory-based study of a helmet with an outer shell created to decrease linear and rotational acceleration Our primary hypothesis was that an outer helmet shell, designed to absorb initial head impacts, would reduce both linear and rotational acceleration. Our objectives were to 1) determine the optimal material for creating a shock-absorbing outer shell and 2) examine the ability of such an outer shell to reduce linear and/or rotational acceleration.

\section{Methods}

We conducted a laboratory-based investigation to cre-

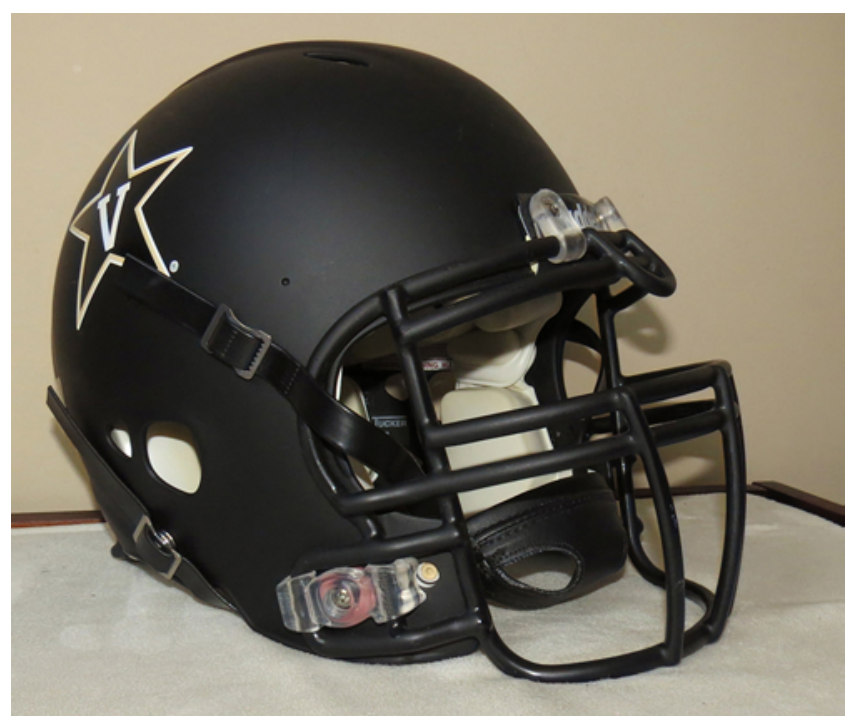

FIG. 1. Riddell Revolution helmet. Figure is available in color online only.

ate and evaluate a football helmet outer-shell prototype. The extra-large Riddell Revolution football helmet, donated by the Vanderbilt University football program, was modified and tested (Fig. 1). The base helmet consisted of a plastic shell and vinyl nitrile interior padding that could be inflated to fit to a player's head. Two helmets were used, 1 control and 1 prototype; the prototype was modified with the addition of an outer shell. Both helmets were 1) used in practice by Vanderbilt University football players, 2) used for 1 year, 3) never reconditioned, and 4) maintained all necessary certifications to be used in National Collegiate Athletic Association (NCAA) football.

\section{Optimal Material Determination \\ Material Selection}

The search for a material to act as the outer shell began with non-Newtonian materials because of their ability to react differently based on the characteristics of an impact. The initial focus was on materials used in other highimpact environments, such as those in equestrian saddle pads (e.g., EquiFit, Inc. and EquiSearch ${ }^{11}$ ). Various materials, including different foams, hydrogels, microbeads, and powders, were considered. However, the polymers used in these applications were not easily accessible because they are specialized materials that are considered proprietary. Furthermore, it was challenging to obtain samples of nonproprietary materials for testing and inclusion in our design. Thus, we chose samples that were easily available, affordable, and representative of the 2 types of non-Newtonian materials with properties that depended on the amount of stress applied (shear-thickening and shear-thinning fluids) versus the time of stress application (thixotropic and rheopectic fluids). Shear-thickening and shear-thinning materials more often exist as polymers, whereas the other non-Newtonian compounds exist as liquids/suspensions and have applications in food processing, oil recovery, emulsions, and polymer solutions, ${ }^{1}$ and such liquid compounds could not be used in this study. 


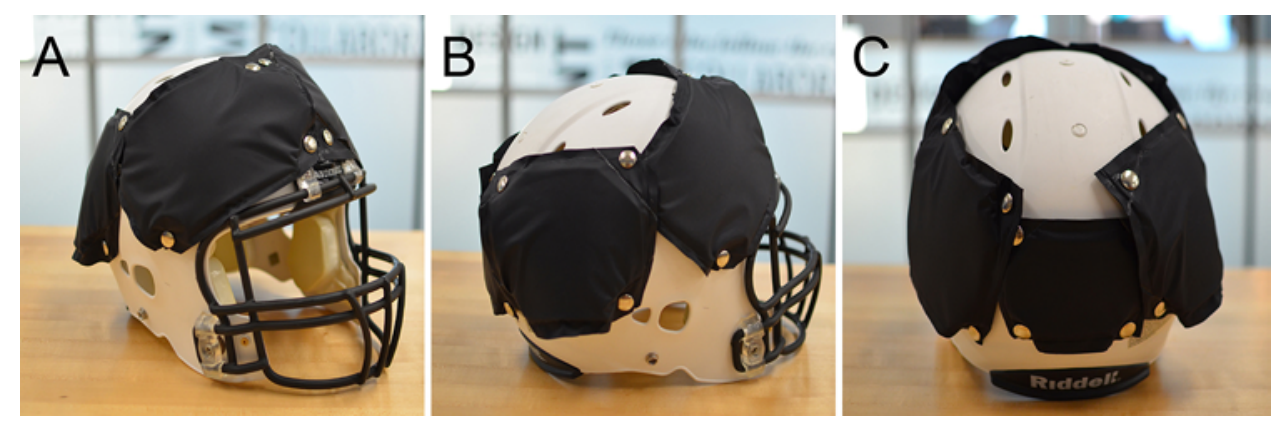

FIG. 2. Shell with EDPs at the front boss (A), side (B), and back (C) of the helmet. Figure is available in color online only.

The following 2 materials were investigated for the proposed outer shell: 1) Dow Corning 3179 Dilatant Compound and 2) Sorbothane Isolate It! (vibration damping sheets). As mentioned, these materials were selected for their non-Newtonian properties, which means that the viscosity of each material changes with the amount of shear stress applied. The Dow Corning material is shear thickening, soft at rest but hardens on impact (i.e., viscosity increases as the rate of shear increases). ${ }^{16}$ In contrast, Sorbothane is shear thinning, solid at rest but becomes more fluid and deformable on impact (i.e., viscosity decreases as the rate of shear increases).$^{18}$ Despite their disparate properties, the malleability of both materials enables dissipation of both linear and rotational acceleration. To assemble for testing, each piece of material $(4 \times 4$ inches, $1 / 4$ inches thick) was sealed inside a water-resistant thermoplastic polyurethane-coated vinyl covering by using an impulse heat sealer. Each vinyl covering was $4.5 \times 4.5$ inches-slightly larger than the material to provide space for movement and deformation. Four metal snaps were added to each corner for future helmet attachment. Here, these vinyl-encased non-Newtonian materials are termed energy-dissipating pods (EDPs).

To determine the optimal outer-shell material, EDPs were first tested in isolation and compared with a control sheet of polycarbonate plastic. Each EDP was tested by using direct-drop tests, which involved dropping 8- and 10-lb medicine balls from a uniform height and measuring the resulting force with a force plate (FP-BTA, Vernier Software and Technology), similar to those previously reported. ${ }^{31}$ Force measurements were recorded (sampling rate $200 \mathrm{~Hz}$ ) and evaluated using custom MATLAB scripts to determine the maximum force of impact from each trial. Thirty trials were performed on each material. The percentage of force reduction from the control to the experimental state with each material was calculated using the following equation: $\%$ force reduction $=\left(\mathrm{F}_{\text {avg control }}\right.$ $\left.-\mathrm{F}_{\text {avg exp }}\right) / \mathrm{F}_{\text {avg control }} \times 100$.

Based on the results of these drop tests, Sorbothane was determined to be the better of the 2 materials for the EDP design (see "Material Selection: Dow Corning Dilatant Compound Versus Sorbothane").

\section{Material Grade Selection}

The optimal material was defined a priori as the one that dissipates the most energy while still returning to its original form. Sorbothane is available in several grades (i.e., 30, 40, 50, 60, and 70 duro, a unit of hardness measured with a durometer). To determine the optimal grade, Sorbothane material of each grade underwent tensile testing using the Instron DynaMight 8800 servohydraulic test system, which calculates force-versus-displacement curves for each material until stretched to failure. ${ }^{4}$ Samples were cut into dog-bone shapes to prevent stress concentrators from causing breakage. The data for Sorbothane material of each grade were analyzed for the following 2 properties: 1) stiffness (slope of the force-versus-displacement curve in the elastic or linear region) and 2) elastic energy dissipation (area under the elastic region of the force-versus-displacement curve). The area under the curve was calculated using a trapezoidal Riemann sum approximation.

After comparing the stiffness and elastic energy dissipation of the various grades, we determined that the 70-duro Sorbothane dissipated the most energy while maintaining its original form without undergoing plastic deformation (see "Material Grade Selection: Sorbothane Grade").

\section{Helmet Testing}

Creation of Outer Shell

Using the 70-duro Sorbothane EDPs, an external shock-absorbing outer shell was created. The final design consisted of 5 EDPs that covered the right and left front boss, the right and left sides, and the back of the helmet (Fig. 2A-C, respectively). Each EDP consisted of a 70duro piece of Sorbothane enclosed inside thermoplastic polyurethane-coated vinyl and attached to the helmet via the screw-snap mechanism at each of its 4 corners. Metal snap fasteners were placed on the outside corners of the EDPs so that they would not interfere with the material inside the sealed region. The snap fasteners were mounted to an area smaller than the corresponding EDP, which facilitated movement, compression, and shock absorption. This feature was intended to translate the energy and improve dissipation during impact testing.

The 2 front, 2 side, and 1 back EDP encased $8.5 \times 6.0$ inch, $6.5 \times 6.0$-inch, and $5.0 \times 4.0$-inch pieces of Sorbothane, respectively. The total Sorbothane volume was 50 cubic inches, which was necessary to cover the most commonly impacted regions adequately while also minimizing the padding to limit the total added weight. With the addition of 18 embedded studs used for the external layer attachment, the base helmet weighed $4.293 \mathrm{lbs}$. The at- 
tachment of all 5 EDPs resulted in a 1.606-lb increase, which resulted in a final helmet weight of $5.899 \mathrm{lbs}$.

After the helmet prototype was completed, the following 2 helmets were used for testing: 1) an experimental helmet, which was modified with EDPs to mimic an outer shell, and 2) a control helmet, which was unmodified.

\section{Head Impacts}

Helmet testing was performed at the Southern Impact Research Center in Knoxville, Tennessee, on the experimental (modified with EDPs) and control (unmodified) helmets. A Hybrid III (RML 121) headform impacted with a pneumatic ram was used to measure and induce acceleration. ${ }^{4}$ The following 3 impact locations were chosen based on the most common sites of impact among collegiate football players: ${ }^{9}$ 1) the front boss, in line with the contralateral front boss; 2 ) the sides, in line with the headform center of mass; and 3) the back, in line with the headform center of mass drop tests that have been found to simulate the rates of game-level rotational acceleration poorly, ${ }^{17}$ whereas pneumatic ram impacts offer a greater range of impact locations and directions. The front boss was the primary location of interest, because these impacts were oblique to the headform center of mass and induced significant rotational acceleration. Each location was impacted 5 times at a speed of $6 \mathrm{~m} / \mathrm{sec}$, which was chosen to produce an approximate acceleration of $80 \mathrm{~g}$ (Video 1).

VIDEO 1. Front boss, side, and back impact testing on a Hybrid III (RML 121) headform was performed with a pneumatic ram to induce and measure acceleration. Copyright Vanderbilt University Medical Center. Published with permission. Click here to view.

\section{Statistical Analysis}

Means and standard deviations were calculated for continuous variables. Two-sample 2-tailed t-tests were performed on all data to evaluate differences between measurements for the control and experimental designs, with $\mathrm{p}<0.05$ denoting significance (Microsoft Excel).

\section{Results}

\section{Optimal Material Determination}

\section{Material Selection: Dow Corning Dilatant Compound Versus}

Sorbothane

The Dow Corning 3179 Dilatant Compound showed a $2.42 \%$ force reduction compared to the polycarbonate plastic control with the 8-lb drop $(\mathrm{p}=0.185)$ and a $7.25 \%$ force reduction with the 10-1b drop $(p=0.009)$. The Sorbothane (50 duro) showed a $5.12 \%$ force reduction with the 8 -lb drop $(\mathrm{p}<0.001)$ and a $10.20 \%$ force reduction with the 10-lb drop ( $\mathrm{p}<0.001$ ) (Fig. 3) compared to control. The Dow Corning compound also experienced permanent deformation, flattening after impact, whereas the Sorbothane recovered from impact with no permanent deformation. These results indicate that Sorbothane was the superior material for outer-shell use.

\section{Material Grade Selection: Sorbothane Grade}

Tensile testing was conducted to measure response to stretch and determine the optimal duro grade of Sorbo-

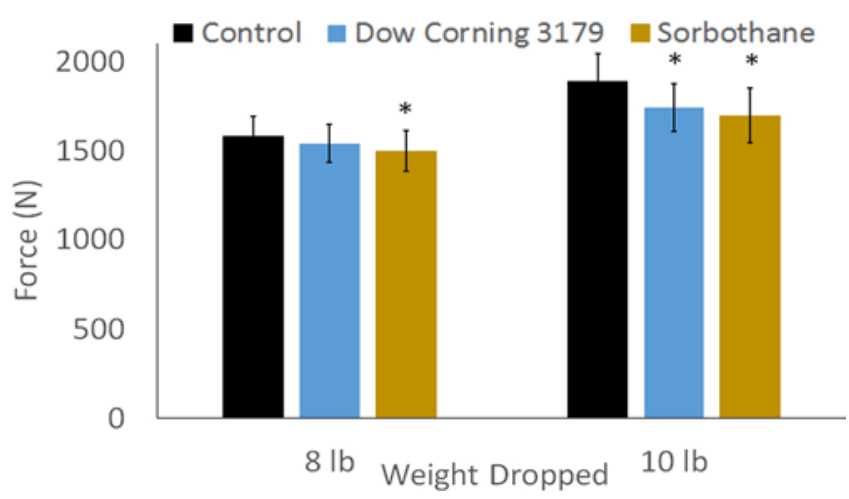

FIG. 3. Forces measured in drop testing on the Dow Corning 3179 and Sorbothane non-Newtonian materials. Asterisk indicates statistical significance. Figure is available in color online only.

thane. Force-versus-displacement curves of each Sorbothane duro grade $(30,40,50,60$, and 70$)$ were generated. The servohydraulic testing machine had a displacement limit of $50 \mathrm{~mm}$, and the 70-duro sample was the only one that experienced failure within that displacement limit, as displayed by the drop-off in the 70-duro curve (Fig. 4A). The material stiffness and the energy dissipated were calculated from the force-versus-displacement curves in the elastic portion of the curve (Table 1). The 70-duro Sorbothane demonstrated the highest area under the curve, elastic energy dissipated, and stiffness. Combined with the greater potential of the higher-duro material to return to its original state, these results indicate that the 70-duro Sorbothane was the optimal material.

Further drop testing of 50- and 70-duro Sorbothane validated the tensile testing results and supported use of the 70-duro Sorbothane (Fig. 4B). Compared to a polycarbonate plastic control, the 50-duro Sorbothane caused a $4.35 \%(\mathrm{p}=0.033)$ force reduction in the 8-lb drop test and a $13.64 \%$ force reduction in the $10-1 b$ drop test $(\mathrm{p}<0.001)$ compared to the 70-duro Sorbothane, which showed an improved force reduction of $14.75 \%(\mathrm{p}<0.001)$ in the $8-\mathrm{lb}$ drop test and a $28.38 \%$ force reduction in the $10-1 \mathrm{~b}$ drop test $(\mathrm{p}<0.001)$. Results of a comparison between the 2 grades of Sorbothane also confirmed that 70-duro Sorbothane outperformed the 50-duro Sorbothane in force reduction in the $8-\mathrm{lb}(\mathrm{p}=0.004)$ and $10-\mathrm{lb}(\mathrm{p}<0.001)$ drop tests.

\section{Helmet Testing}

Pneumatic ram testing on the modified helmet revealed significant reductions in both linear and rotational acceleration (Table 2) compared to those on the control helmet. For linear acceleration, the EDPs produced modest reductions of $5.8 \%(p<0.001)$ and $10.8 \%(p=0.033)$ at the side and front boss locations, respectively (Fig. 5A). For rotational acceleration, the EDPs produced a substantial reduction of $49.8 \%(\mathrm{p}<0.001)$ at the front boss location (Fig. 5B).

\section{Discussion}

In this laboratory-based study, we tested the concept of 

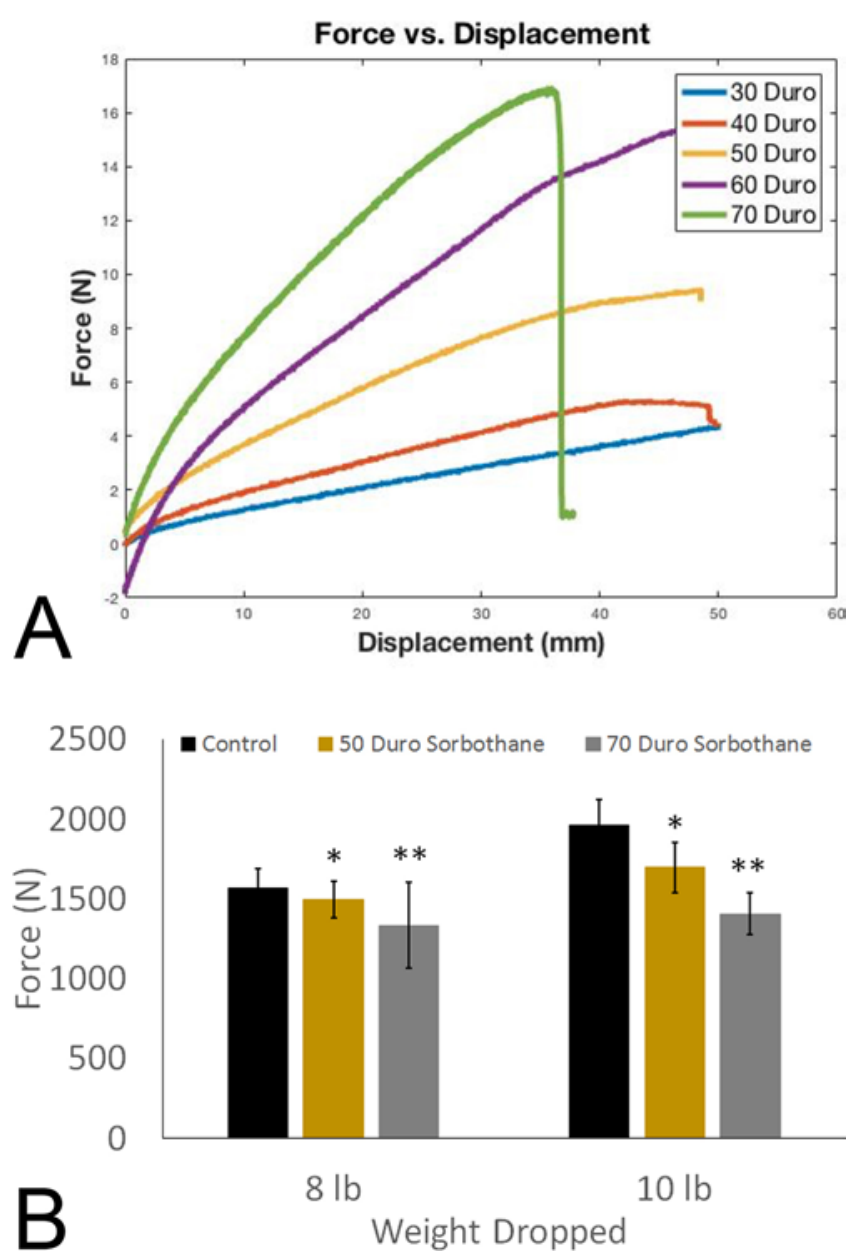

FIG. 4. A: Force-versus-displacement curves determined via tensile testing for the various Sorbothane grades. The testing apparatus had a displacement limit of $50 \mathrm{~mm}$, and the 70-duro sample was the only one that experienced failure within that displacement limit, as displayed by the drop-off in the 70-duro curve. B: Drop-testing results validated the use of 70-duro Sorbothane. Asterisk indicates significant difference between control and 50-duro Sorbothane; double asterisks indicate significant difference between control and 70-duro Sorbothane. Figure is available in color online only.

a football helmet prototype with an outer shell designed to reduce both linear and rotational acceleration. Between 2 non-Newtonian materials tested, 70-duro Sorbothane was superior in terms of force reduction, energy dissipation, and material stiffness. After creating the helmet prototype with 5 EDPs filled with 70-duro Sorbothane and subjecting it to several head impacts, linear acceleration was marginally reduced at the side and front boss locations, whereas rotational acceleration was reduced substantially at the front boss location. Although this laboratory-based experiment was far from on-field implementation, the implications of our findings reveal potential for future study.

The use of non-Newtonian materials to mitigate forces is not novel; Sorbothane was investigated for use in mouth guards ${ }^{3}$ and shoe liners ${ }^{5}$ nearly 30 years ago. Today, the use of non-Newtonian materials in protective equipment remains viable. Fowler et al. ${ }^{13}$ compared the force-mitigat-
TABLE 1. Sorbothane properties determined from tensile testing

\begin{tabular}{ccc}
\hline $\begin{array}{c}\text { Sorbothane Grade } \\
\text { (duro) }\end{array}$ & $\begin{array}{c}\text { Elastic Energy Dissipated } \\
(\mathrm{mJ})\end{array}$ & $\begin{array}{c}\text { Stiffness } \\
(\mathrm{N} / \mathrm{mm})\end{array}$ \\
\hline 30 & 120.9 & 0.0787 \\
\hline 40 & 121.5 & 0.109 \\
\hline 50 & 208.7 & 0.190 \\
\hline 60 & 235.8 & 0.332 \\
\hline 70 & 294.9 & 0.331 \\
\hline
\end{tabular}

ing ability of a nanocomposite shear-thickening material (silica particles suspended in polyethylene glycol) to 33 $\mathrm{mm}$ of internal foam padding from a Riddell Revolution helmet and found that, although both materials performed similarly at lower-energy impacts, the nanocomposite shear-thickening material dissipated more force at higherenergy impacts. Although the materials were never tested within a helmet construct, our results provide strong evidence to promote the use of non-Newtonian materials in such an application. Interesting is that we found that the shear-thinning material Sorbothane dissipated energy better than a shear-thickening material. One explanation for this finding could be that our material was tested against the hard plastic shell of a helmet; the shear-thickening Dow Corning material underwent plastic deformation, whereas the shear-thinning Sorbothane material returned to its original state. Nonetheless, non-Newtonian materials show great promise for improving football helmet safety.

The study of laboratory-based design of novel helmets for football has been sparse.,225 Nakatsuka and Yamamoto $^{25}$ added a soft cushion layer to the helmet exterior in an attempt to reduce the magnitude of head impacts. One helmet had a foam pad fixed to the crown and struck a second helmet with a foam pad fixed to the side, and after 90 total impacts, the foam layer of both helmets significantly reduced head impact-severity measures. ${ }^{25}$ However, the study was limited by the low forces $(30 g)$ used, lack of rotational acceleration testing, and absence of a statistical analysis. Most recently, Breedlove et al. ${ }^{2}$ found that the addition of an outer cap to a commonly used football helmet did not reduce rates of linear acceleration significantly after subjecting it to 18 total tests on 6 locations at 3 different velocities.

Regarding the risk of SRC, few studies have found that different helmets are associated with different injury profiles. Rowson et al. ${ }^{29}$ retrospectively reviewed data from 1833 collegiate football players with instrumented Riddell VSR4 and Riddell Revolution helmets who suffered a total of 64 concussions between 2005 and 2010. After controlling for head impact exposure, a 53.9\% reduction in SRC risk was associated with the Revolution helmet compared to that with the VSR4. The authors concluded that helmet type and design conferred various concussion risks and acceleration magnitudes. These results are supported further by an earlier prospective study of high school football players, which found a 31\% decreased relative risk of SRC with the Revolution helmet compared to that with standard helmets. ${ }^{7}$ A third study of 2900 high school foot- 
TABLE 2. Helmet testing results according to impact location and linear/rotational acceleration

\begin{tabular}{ccc}
\hline & \multicolumn{2}{c}{ Force } \\
\cline { 2 - 3 } Impact Location & Linear $(g)$ & Rotational $\left(\mathrm{r} / \mathrm{sec}^{2}\right)$ \\
\hline Front boss & \\
\hline Control & 89.5 & $9,312.8$ \\
\hline Outer shell & 79.8 & $4,671.7$ \\
\hline p value & $0.033^{*}$ & $<0.001^{*}$ \\
\hline Side & & \\
\hline Control & 75.4 & $3,676.4$ \\
\hline Outer shell & 71.1 & $3,829.16$ \\
\hline p value & $<0.001^{*}$ & 0.394 \\
\hline Back & & $4,695.3$ \\
\hline Control & 64.5 & 0.253 \\
\hline Outer shell & 65.9 & 0.815 \\
\hline p value & $4,720.3$ &
\end{tabular}

* Statistically significant $(p<0.05)$.

ball players with concussion concluded that the number of symptoms, symptom types, and time to return to play were similar in patients who were wearing a Riddell or Schutt helmet but worse for those who wore an Adams, Rawlings, or Xenith helmet. ${ }^{6}$ Despite the 3 aforementioned studies concluding a difference in concussion risk based on helmet manufacturer, a recent study found no such difference. ${ }^{24}$ Thus, helmet materials and design seem to play a significant role in SRC risk and associated linear and rotational accelerations, although efforts to study them remain ongoing.

Outside the scientific literature, the helmet market includes many intriguing designs with similar outer-shell concepts; however, rigorous scientific study of them has been lacking. One such design is that of the Zerol helmet (VICIS, Inc.), which includes a deformable outer skin that gives when struck, with hard plastic below, and reportedly reduces force transmitted to the brain. A second helmet is the Schutt F7, which features a "Tektonic plate" that covers the crown and back of the helmet, and a new interior "radian diffusion system" liner that reportedly improves movement between the liner and head to combat rotational forces. Third, the Xenith company touts the EPIC and $\mathrm{X} 2 \mathrm{E}$ helmets, both of which include a compression liner and suspension system, which allows the helmet and shell to move independently, reportedly mitigating rotational forces. Although the company has done impressive Web marketing, we found no peer-reviewed studies in which these novel helmets were evaluated. Without rigorous, independent testing, the scientific community cannot empirically determine the value of such innovative designs.

The results of our laboratory-based study provide insight into the utility of an outer-shell design, and we characterized a non-Newtonian material (70-duro Sorbothane) to be used in such a shell. Significant reductions in rotational acceleration were obtained at the front boss location. For our future work, we plan to pursue a practice- and game-ready helmet design by securely covering
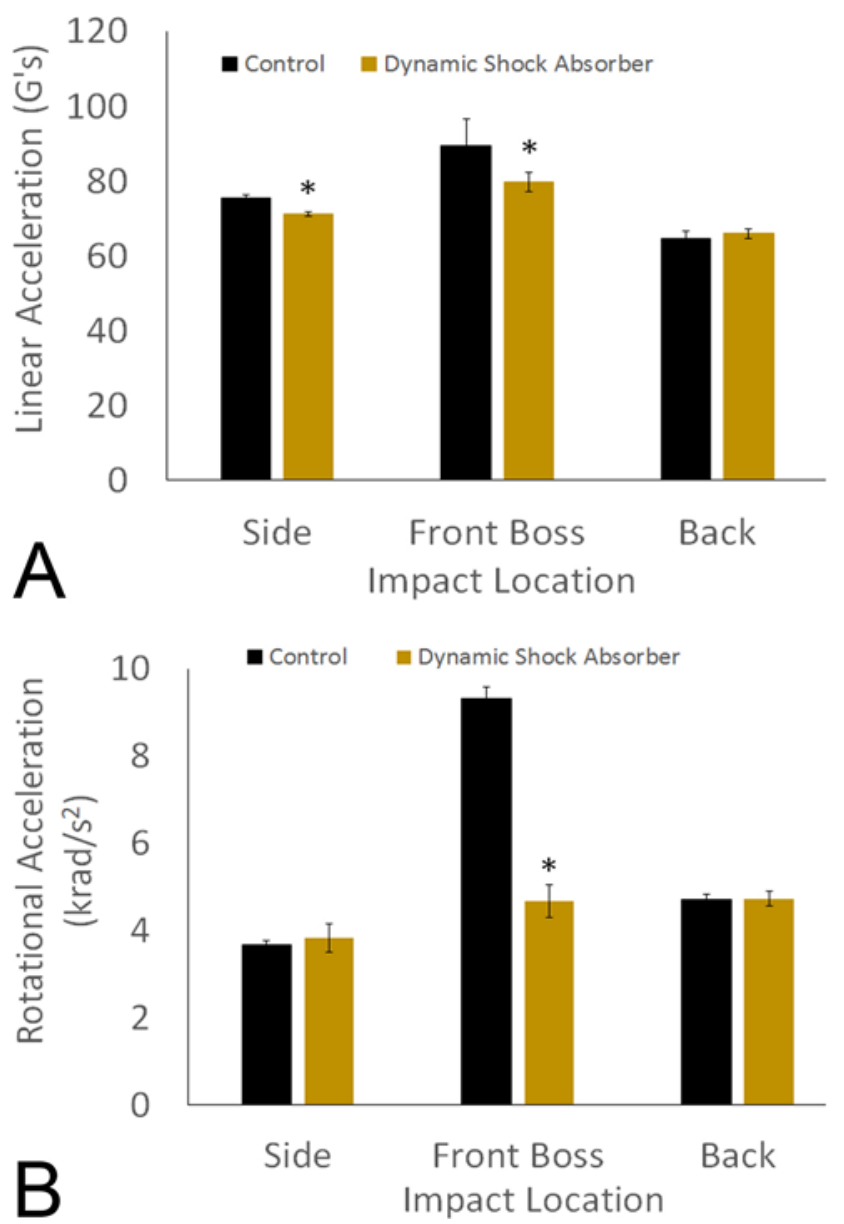

FIG. 5. A: Linear acceleration experienced by the Hybrid III headform with the control and experimental helmets after $6 \mathrm{~m} / \mathrm{sec}$ linear impacts at the 3 given locations. B: Rotational acceleration experienced by the Hybrid III headform with the control and experimental helmets after $6 \mathrm{~m} /$ sec linear impacts at the 3 given locations. G's, acceleration $(g)$; asterisk indicates statistical significance. Figure is available in color online only.

the entire helmet with a Sorbothane shell, coupled with helmet accelerometers to monitor practice and in-game head accelerations. It is our hope that researchers can further expand on our findings, specifically the importance of non-Newtonian and shear-thinning materials to attenuate rotational acceleration. Although novel and presumably innovative football helmets are marketed aggressively, their performance details are unavailable to independent researchers. Similarly, empirical data regarding the ability of newer helmets to reduce head acceleration, and possibly concussion risk, are unknown. Without objective data, it is unknown whether true reductions in rotational acceleration occur and, if so, whether these reductions are clinically and biomechanically meaningful. It is our hope that these results are only the beginning of publicly available and peer-reviewed data from investigations of novel helmet modifications and designs.

To build on this work, several steps can be taken to improve the evaluation of novel football helmets. First, it is imperative that investigators continue rigorous testing of publicly available helmets for linear and rotational ac- 
celeration, because such work builds the groundwork for more innovative research. Second, collaborations with industry to evaluate current equipment should be pursued by researchers and/or sports safety-promoting organizations. An example can be seen with the helmet add-on device Guardian Cap, studied by Breedlove et al., ${ }^{2}$ who tested it in a controlled setting. Third, the power of professional sports organizations should be used to award both industry and independent researchers for collaborative and transparent helmet research.

Our study is not without limitations. First, although rigorous scientific investigation was undertaken, the current design remains experimental in nature. Substantial refinements in form factor, manufacturing, and testing are needed to take this proof-of-concept study into a live setting. Second, only 2 materials were selected for testing, and other non-Newtonian materials might provide better results. Non-Newtonian materials come mostly in the form of fluids, ${ }^{1}$ and the solids that do exist were less convenient to use than the compounds used. Future investigators should be aware of other possible non-Newtonian compounds, which include oxide and metallic glass-forming materials ${ }^{32}$ and crystal compounds. ${ }^{30}$ Third, each helmet underwent only 5 impacts at each location, which is likely not enough to fully evaluate the durability of each material. Fourth, it remains unknown as to how these acceleration reductions might affect concussion risk, because we included laboratory testing only. Fifth, the prototype helmet added $1.606 \mathrm{lbs}$ of external padding, and it is possible that the increased weight alone might have affected reductions in acceleration. Because a standard force was applied to the helmet, and mass and acceleration are related indirectly, any increase in mass theoretically could have resulted in decreased acceleration for the same applied force. The control helmet ideally would have had an added weight of $1.606 \mathrm{lbs}$, without extra padding, to standardize weight measurements. Last, the current helmets donated from a Division I NCAA football program had been used for 1 year, and our results might have differed had a newer or older helmet been used.

\section{Conclusions}

Our laboratory-based study evaluated a novel football helmet prototype with an outer shell that was aimed at reducing linear and rotational acceleration. Sorbothane (70 duro) emerged as the optimal outer-shell material, and the helmet outer-shell prototype demonstrated a 5\%-10\% reduction in linear acceleration and $50 \%$ reduction in rotational acceleration for the off-center front boss impacts. The substantial reduction in rotational acceleration that we found reveals potential for future helmet design, especially given the paucity of publicly reported scientific helmet-design literature.

\section{Acknowledgments}

We thank Kevin Galloway, Jeff Nyman and his research lab, and the Vanderbilt University Football program, in addition to Elizabeth McCalley, David Halstead, and the Southern Impact Research Center, which provided all necessary helmet impacttesting equipment.

\section{References}

1. Ahmed A, Siddique JI, Mahmood A: Non-Newtonian flowinduced deformation from pressurized cavities in absorbing porous tissues. Comput Methods Biomech Biomed Engin 20:1464-1473, 2017

2. Breedlove KM, Breedlove E, Nauman E, Bowman TG, Lininger MR: The ability of an aftermarket helmet add-on device to reduce impact-force accelerations during drop tests. J Athl Train 52:802-808, 2017

3. Bulsara YR, Matthew IR: Forces transmitted through a laminated mouthguard material with a Sorbothane insert. Endod Dent Traumatol 14:45-47, 1998

4. Campbell KR, Warnica MJ, Levine IC, Brooks JS, Laing AC, Burkhart TA, et al: Laboratory evaluation of the gForce Tracker $^{\mathrm{TM}}$, a head impact kinematic measuring device for use in football helmets. Ann Biomed Eng 44:1246-1256, 2016

5. Cinats J, Reid DC, Haddow JB: A biomechanical evaluation of sorbothane. Clin Orthop Relat Res (222):281-288, 1987

6. Collins CL, McKenzie LB, Ferketich AK, Andridge R, Xiang $\mathrm{H}$, Comstock RD: Concussion characteristics in high school football by helmet age/recondition status, manufacturer, and model: 2008-2009 through 2012-2013 academic years in the United States. Am J Sports Med 44:1382-1390, 2016

7. Collins M, Lovell MR, Iverson GL, Ide T, Maroon J: Examining concussion rates and return to play in high school football players wearing newer helmet technology: a three-year prospective cohort study. Neurosurgery 58:275-286, 2006

8. Comstock RD, Currie DW, Pierpoint LA: Summary Report: National High School Sports-Related Injury Surveillance Study. Denver: Colorado School of Public Health, 2016 (http://www.ucdenver.edu/academics/colleges/PublicHealth/ research/ResearchProjects/piper/projects/RIO/Documents/ Original\%20Report_\%202014_15.pdf) [Accessed March 6, 2018]

9. Crisco JJ, Fiore R, Beckwith JG, Chu JJ, Brolinson PG, Duma S, et al: Frequency and location of head impact exposures in individual collegiate football players. J Athl Train 45:549-559, 2010

10. Duhaime AC, Beckwith JG, Maerlender AC, McAllister TW, Crisco JJ, Duma SM, et al: Spectrum of acute clinical characteristics of diagnosed concussions in college athletes wearing instrumented helmets: clinical article. J Neurosurg 117:1092-1099, 2012

11. EquiSearch: High tech saddle pads. EquiSearch. May 24, 2009. (https://www.equisearch.com/articles/high_tech saddle_pads_052409) [Accessed March 6, 2018]

12. Forbes JA, Awad AJ, Zuckerman S, Carr K, Cheng JS: Association between biomechanical parameters and concussion in helmeted collisions in American football: a review of the literature. Neurosurg Focus 33(6):E10, 2012

13. Fowler JN, Pallanta AA, Swanik CB, Wagner NJ: The use of shear thickening nanocomposites in impact resistant materials. J Biomech Eng 137:054504, 2015

14. Gessel LM, Fields SK, Collins CL, Dick RW, Comstock RD: Concussions among United States high school and collegiate athletes. J Athl Train 42:495-503, 2007

15. Harman D, Young PG, Cotton R, Gerber B, Quan C, Marchal $\mathrm{T}$, et al: Reducing the Risk of Concussion through Personalized Helmet Design. (https://www.researchgate.net/ publication/311485071) [Accessed March 6, 2018]

16. Hayes SG, Venkatraman P: Materials and Technology for Sportswear and Performance Apparel. Boca Raton: CRC Press, 2016

17. Hernandez F, Shull PB, Camarillo DB: Evaluation of a laboratory model of human head impact biomechanics. J Biomech 48:3469-3477, 2015

18. Khan MMA, Shahzad A: Boundary layer flow and heat transfer for a third grade fluid over a nonlinear radially stretching sheet. Walailak J Sci Technol 14:157-168, 2017 
19. King AI, Yang KH, Zhang L, Hardy W, Viano DC: Is head injury caused by linear or angular acceleration?, in International Research Conference on the Biomechanics of Impact (IRCOBI), 2003 (http://snellfoundation.net/docs/ articles/hic/King_IRCOBI_2003.pdf) [Accessed March 1, 2018]

20. Kirkwood MW, Yeates KO, Wilson PE: Pediatric sportrelated concussion: a review of the clinical management of an oft-neglected population. Pediatrics 117:1359-1371, 2006

21. Kuhn AW, Yengo-Kahn AM, Kerr ZY, Zuckerman SL: Sports concussion research, chronic traumatic encephalopathy and the media: repairing the disconnect. Br J Sports Med 51:1732-1733, 2017

22. Lange K: How Army research is combating concussions in the NFL. DoDLive.com. February 4, 2018. (http://www. dodlive.mil/2016/02/04/how-army-research-is-combatingconcussions-in-the-nfl/) [Accessed March 1, 2018]

23. Lovell MR, Fazio V: Concussion management in the child and adolescent athlete. Curr Sports Med Rep 7:12-15, 2008

24. McGuine TA, Hetzel S, McCrea M, Brooks MA: Protective equipment and player characteristics associated with the incidence of sport-related concussion in high school football players: a multifactorial prospective study. Am J Sports Med 42:2470-2478, 2014

25. Nakatsuka AS, Yamamoto LG: External foam layers to football helmets reduce head impact severity. Hawaii J Med Public Health 73:256-261, 2014

26. O'Connor KL, Baker MM, Dalton SL, Dompier TP, Broglio SP, Kerr ZY: Epidemiology of sport-related concussions in high school athletes: National Athletic Treatment, Injury and Outcomes Network (NATION), 2011-2012 through 20132014. J Athl Train 52:175-185, 2017

27. Rowson S, Duma SM: Brain injury prediction: assessing the combined probability of concussion using linear and rotational head acceleration. Ann Biomed Eng 41:873-882, 2013

28. Rowson S, Duma SM, Beckwith JG, Chu JJ, Greenwald RM, Crisco JJ, et al: Rotational head kinematics in football impacts: an injury risk function for concussion. Ann Biomed Eng 40:1-13, 2012

29. Rowson S, Duma SM, Greenwald RM, Beckwith JG, Chu JJ, Guskiewicz KM, et al: Can helmet design reduce the risk of concussion in football? J Neurosurg 120:919-922, 2014

30. Sarman S, Wang YL, Laaksonen A: Non-Newtonian rheological properties of shearing nematic liquid crystal model systems based on the Gay-Berne potential. Phys Chem Chem Phys 17:16615-16623, 2015

31. Viano DC, Withnall C, Wonnacott M: Football helmet drop tests on different fields using an instrumented Hybrid III head. Ann Biomed Eng 40:97-105, 2012
32. Zhu W, Aitken BG, Sen S: Communication: non-Newtonian rheology of inorganic glass-forming liquids: universal patterns and outstanding questions. J Chem Phys 146:081103, 2017

\section{Disclosures}

Dr. Solomon receives consulting fees from the Nashville Predators (National Hockey League), the Tennessee Titans (National Football League [NFL]), University of Tennessee Athletics, Tennessee Tech Athletics, and the NFL; fees are paid to his institution. In addition, he is a consultant to the NFL Department of Health and Safety.

\section{Author Contributions}

Conception and design: Zuckerman, Reynolds, Yengo-Kahn, Kuhn, Solomon. Acquisition of data: Chadwell, Goodale, Lafferty, Langford, McKeithan. Analysis and interpretation of data: Zuckerman, Reynolds, Yengo-Kahn, Kuhn, Chadwell, Goodale, Lafferty, Langford, McKeithan. Drafting the article: Zuckerman, Reynolds, Yengo-Kahn, Kuhn, Chadwell, Goodale, Lafferty, Langford, McKeithan. Critically revising the article: Zuckerman, Reynolds, Yengo-Kahn, Kuhn, Kirby, Solomon. Reviewed submitted version of manuscript: Zuckerman, Reynolds, Yengo-Kahn, Kuhn, Kirby. Approved the final version of the manuscript on behalf of all authors: Zuckerman. Statistical analysis: Zuckerman, Chadwell, Goodale, Lafferty, Langford, McKeithan. Administrative/technical/material support: Zuckerman, Yengo-Kahn, Kirby, Solomon. Study supervision: Zuckerman, Solomon. Video creation: Kirby.

\section{Supplemental Information Videos}

Video 1. https://vimeo.com/256961683.

\section{Previous Presentations}

Portions of this work were presented in abstract/oral presentation form at the 2017 Tennessee Neurosurgical Society Meeting held in Nashville, TN, on August 12, 2017, and the 2018 American Association of Neurological Surgeons Conference held in New Orleans, LA, on May 1, 2018.

\section{Correspondence}

Scott L. Zuckerman: Vanderbilt University School of Medicine, Nashville, TN. scott.zuckerman@vanderbilt.edu. 